\title{
Movements, habitat utilization, and post-release survival of cobia (Rachycentron canadum) that summer in Virginia waters assessed using pop-up satellite archival tags
}

\author{
Douglas R. Jensen ${ }^{*}(10$ and John E. Graves
}

\begin{abstract}
Background: Cobia (Rachycentron canadum) is a cosmopolitan marine fish that inhabits tropical, sub-tropical, and temperate marine and estuarine waters and supports a major recreational fishery along the U.S. Atlantic and Gulf of Mexico coasts. Recent changes in U.S. cobia management have sparked controversy and highlighted limitations in our understanding of the species' biology. This study utilized pop-up satellite archival tags (PSATs) to assess the movements, habitat utilization, and post-release survival of cobia that summer in Virginia waters.

Results: PSATs were deployed on 36 cobia caught in Virginia state waters using standard recreational techniques in August 2016 and August-September 2017. All fish larger than 37-in total length were tagged, and several of these were hooked deeply. No mortalities were inferred for the 20 cobia whose PSATs reported and remained attached for at least 10 days. Premature release of tags was an issue, and only five PSATs remained attached for the full 180-day deployment period. Some fish undertook long seasonal movements, with one individual entering Florida waters well beyond the current stock demarcation boundary. Several fish overwintered in waters offshore of North Carolina near the continental shelf break. Cobia demonstrated a strong affinity for waters $\geq 20^{\circ} \mathrm{C}$, even in the coldest months. They displayed distinct seasonal differences in habitat utilization, spending high proportions of their time near the surface during the summer months and extended periods at depths $\geq 20 \mathrm{~m}$ in the winter months.
\end{abstract}

Conclusions: Cobia are hardy fish with low post-release mortality when handled respectfully. Their migratory patterns are clearly temperature driven, and seasonal changes in habitat utilization means varied vulnerability to fishing gears. Further understanding of cobia migratory patterns, particularly in conjunction with spawning activity, is needed to best manage this species.

Keywords: Rachycentron canadum, Cobia, Pop-up satellite archival tags, PSAT, Post-release mortality, Habitat utilization, Migration, Recreational fishery

\section{Introduction}

Cobia (Rachycentron canadum) is a cosmopolitan marine fish species occurring in tropical, sub-tropical, and temperate marine and estuarine waters throughout much of

*Correspondence: DouglasRayJensen@iCloud.com

Virginia Institute of Marine Science, William and Mary, 1375 Greate Road, Gloucester Point, VA 23062, USA the world's oceans [24]. The species supports commercial and recreational fisheries throughout much of its range and aquaculture production is now beginning to rival production from capture fisheries [13]. Along the U.S. Atlantic and Gulf of Mexico coasts, cobia have been targeted by commercial and recreational fisheries since before the turn of the twentieth century, with the

(c) The Author(s) 2020. This article is licensed under a Creative Commons Attribution 4.0 International License, which permits use, sharing, adaptation, distribution and reproduction in any medium or format, as long as you give appropriate credit to the original author(s) and the source, provide a link to the Creative Commons licence, and indicate if changes were made. The images or other third party material in this article are included in the article's Creative Commons licence, unless indicated otherwise in a credit line to the material. If material is not included in the article's Creative Commons licence and your intended use is not permitted by statutory regulation or exceeds the permitted use, you will need to obtain permission directly from the copyright holder. To view a copy of this licence, visit http://creativeco mmons.org/licenses/by/4.0/. The Creative Commons Public Domain Dedication waiver (http://creativecommons.org/publicdomain/ zero/1.0/) applies to the data made available in this article, unless otherwise stated in a credit line to the data. 
recreational fishery accounting for $80-95 \%$ of U.S. annual cobia harvest in recent decades [23].

Cobia are managed in U.S. waters as two stocks, the Atlantic Migratory Group and the Gulf Migratory Group. Prior to 2015, the demarcation line between the two stocks was set at the Florida Keys, consistent with conventional tagging data that demonstrated very limited exchange ( $\sim$ 1\%) between the Atlantic and Gulf of Mexico [22]. Based on additional tagging and genetic studies, the stock boundary was moved northward to the GeorgiaFlorida state line in 2015 [23].

Cobia often undergo seasonal migration patterns, moving from tropical and sub-tropical waters into more temperate zones in the summer months, and some fish in the Atlantic Migratory Group exhibit this behavior. Cobia are multiple batch spawners, with spawning occurring along the U.S. Atlantic coast from May-October [26]. Eggs have been found in estuaries and across coastal waters, but the spawning habits of cobia have not been thoroughly studied [11].

The most recent baseline stock assessment for cobia in U.S. Atlantic waters was conducted in 2012 and determined that neither cobia stock was overfished or experiencing overfishing [23]. The Atlantic Migratory Group was deemed healthy with spawning stock biomass at 1.75 times that required for maximum sustainable yield (MSY), and fishing mortality $(F)$ was below the threshold for maintaining biomass at or above MSY $\left(F_{\text {MSY }}\right)$, with $F / F_{\text {MSY }}=0.42$ in 2011 [23].

Despite the healthy status of the Atlantic Migratory Group at the time of the last assessment, there have been concerns over recent estimates of recreational catches. When the new management boundaries were put in place in 2015, the recreational allowable catch limit (ACL) was split, with $620,000 \mathrm{lb}(281,227 \mathrm{~kg})$ allocated to the states from Georgia northward and 840,000 lb $(381,018 \mathrm{~kg})$ allocated to the east coast of Florida, an allocation that did not necessarily reflect historical landings [19]. In 2015 and 2016, estimated landings of fish from the Atlantic Migratory Group were 1.57 and 1.34 million $\mathrm{lb}(712,140$ and $607,814 \mathrm{~kg})$, respectively, well above the ACL of $620,000 \mathrm{lb}(281,227 \mathrm{~kg})$. Virginia was the single greatest contributor to these totals with back-toback record estimated catches of 882,000 and 915,000 lb $(400,068$ and $415,037 \mathrm{~kg})$, both far in excess of the entire regional ACL.

Because of the estimated overharvest, the recreational cobia season in federal waters (waters greater than 3 miles from shore) was closed for the first time in June 2016, following the 2015 harvest estimate of $248 \%$ of the ACL [5]. Southeast Atlantic states with cobia fisheries (Virginia, North Carolina, South Carolina, and Georgia) reacted by tightening regulations (minimum size and bag limits) and seasons in their state waters (waters within 3 miles of shore) to prevent a complete fishery closure. Despite area closures and more stringent state-specific management measures, the 2016 estimated recreational harvest exceeded 1.3 million pounds, $217 \%$ of the ACL [20]. As a result, the 2017 season was completely closed in federal waters [6], a measure that had differential impacts on state recreational fisheries depending on the prevalence of cobia in state or federal waters.

These restrictions combined with uncertainty regarding stock structure and amended stock definitions have highlighted limitations on our understanding of cobia biology in addition to creating controversy among management and stakeholders [4]. The 2012 stock assessment made several recommendations that could provide better insights into cobia population dynamics; these included studies of stock structure (employing genetic and conventional/telemetry tagging methodologies), movements, and post-release survival. This study addresses some of these research needs by using pop-up satellite archival tags (PSATs) to investigate seasonal movements, habitat utilization, and post-release survival of cobia that summer in Virginia coastal waters. PSATs can provide timely assessments of movement patterns, providing information necessary to develop biologically meaningful stock boundaries. The habitat utilization data collected by PSATs also give insights on the vulnerability of cobia to various fishing gears, allowing a better translation of catch-per-unit-effort data to abundance. Finally, postrelease mortality of cobia caught in the recreational fishery can be directly inferred from PSAT data, providing information needed to better estimate recreational fishing mortality-an estimate which has heightened importance given new regulations that are likely to increase regulatory discards.

\section{Materials and methods}

All angling and tagging procedures were approved by the William \& Mary Institutional Animal Care and Use Committee (IACUC-2016-07-25-11296-jegrav) and complied with all relevant state and federal regulations.

Three different PSAT models were used in this study: the mrPAT (Wildlife Computers, Redmond, WA), and the X-Tag and PTT-100 (Microwave Telemetry Inc., Columbia, MD). The Microwave Telemetry, Inc. (MTI) tags, available from previous studies, record light, pressure (depth), and temperature data which are summarized at 15- or 30-min intervals. These tags were primarily deployed in the first year of the study and provided relatively high-resolution habitat information. The less expensive Wildlife Computers (WC) mrPAT tags were selected for the second year because of their lower cost which allowed for the greatest possible sample size 
to study seasonal fish movements. This tag model is primarily designed for studies of fish movement, although post-release mortality may be inferred from the archived inclinometer data. The mrPAT tag records (and subsequently transmits following release from the fish) daily maximum and minimum environmental temperatures and the average of the daily maximum and minimum tag inclination values.

All tag models were programmed to release after 6 months, and premature release options were activated for two of the tag models. X-Tags were programmed to initiate the release/transmit sequence if the tag remained at a constant depth $( \pm 3 \mathrm{~m})$ for 4 consecutive days. The PTT-100 "constant depth" feature was not activated as it would initiate the release/transmit sequence when a tag remained at constant depth with coarser resolution $( \pm 10 \mathrm{~m})$ for 4 consecutive days. The Chesapeake Bay is sufficiently shallow that premature releases would be highly likely with a constant depth threshold that incorporated a depth range of $\pm 10 \mathrm{~m}$, as deeper habitat is not available in many areas. The mrPAT tags contain a wet/ dry conductivity sensor and were programmed to release from the fish prematurely when a tag was "dry" (at the surface) for a total of 6 min in any rolling 2-h window (with sampling interval of $3 \mathrm{~s}$ ).

Cobia were caught and tagged in the Chesapeake Bay or in coastal waters within 3 miles $(4.8 \mathrm{~km})$ of the Virginia shoreline by recreational anglers (both private and charter) using methods of their choice which we considered to be representative of typical recreational fishing practices in Virginia. The most common methods of fishing for cobia were chumming and sight-casting using live or artificial baits rigged with J-hooks or circle hooks, or lures rigged with J-hooks. Fish were hooked, landed, netted, and brought into the boat for measurement and tag attachment. Data recorded for each fish included total length, estimated weight, fight time, air exposure time, bait, hook type, hooking location, release coordinates, and any observational notes. Length and estimated weight were recorded in inches and pounds, as those are standard units for recreational anglers, and later converted to metric units for this report. Hooking location was defined as superficial (lodged in the jaw or mouth with part of the hook externally visible) or deep (esophagus, gut, or location not externally visible).

PSATs were attached to all cobia, regardless of condition, that exceeded a minimum length threshold set for each tag model: 37 in $(94 \mathrm{~cm})$ total length $(\mathrm{TL})$ [equivalent to the federal minimum size of 33 in $(84 \mathrm{~cm})$ fork length] for the WC mrPAT and MTI X-Tag; and 45 in $(114.3 \mathrm{~cm})$ TL for the larger MTI PTT-100. Tags were attached to fish using standard methods developed by Graves et al. [10]. Each PSAT was attached to an intramuscular anchor (dart) using a $36.4 \mathrm{~kg}$ test monofilament tether $16 \mathrm{~cm}$ in length. The dart was inserted to a depth of approximately $5 \mathrm{~cm}$ into the fish musculature below the posterior dorsal fin and well above the coelomic cavity, with the dart presumably interlocking with the pterygiophores. Fish were subsequently released as quickly as possible.

\section{Data analysis}

The data received from the transmitting tags were used to determine net travel distance, habitat utilization, and rates of post-release survival. Net travel distance was defined as the minimum straight-line distance between the location of fish release and the first precise transmission location report. Only transmissions with Advanced Research and Global Observation Satellite (ARGOS) location codes 1, 2, or 3 were used, ensuring that transmitting locations were determined with $1.5 \mathrm{~km}$ precision. Average daily displacement was calculated as the net travel distance divided by the time the PSAT remained attached to the fish (deployment duration).

Depth and temperature data were used to describe individual habitat utilization and to assess possible changes in habitat utilization associated with diurnal cycles, lunar cycles, and seasons. Data were summarized to assess percentage of time spent at different water temperatures and depths by month and by fish. These summaries use data aggregated from all tags. This aggregation is not ideal because the results may be biased toward tags that transmitted more data, but it was necessary with the limited amount of data available. Contributions were weighted by tag to assess and minimize these biases. Summaries of depth and temperature frequencies were weighted such that each tag contributed an equal proportion for each assessment if tags reported unequal data. Pearson's Chi square tests were used to evaluate differences between raw and weighted data distributions with alpha $=0.05$. Raw data distributions were used if there were no meaningful differences with weighted distributions.

Diurnal analyses compared observations grouped by day and night. Since precise sunrise and sunset times were not known and varied over the course of the study, day observations were defined as the periods of 1213 to 2152 GMT each day, a time window corresponding with sunrise to sunset for the winter solstice in Virginia Beach, Virginia. Similarly, night observations were defined as the periods 0040 to $0940 \mathrm{GMT}, 30 \mathrm{~min}$ after sunset to $30 \mathrm{~min}$ before sunrise for Virginia Beach, Virginia on August 1 st, the longest day length in this study. Defining these windows for day and night enabled data sorting with certainty that a given observation was a true day or night observation, respectively. Any observation not falling 
within these time slots was considered crepuscular data and not included in diurnal data analyses.

Moon phase analyses similarly grouped data distributions by the four primary lunar phases: new moon, first quarter moon, full moon, and third quarter moon. Data were assigned to each of these four primary phases if an observation was made within \pm 2 days of the phase peak as defined by the U.S. Naval Observatory. Any data falling outside these 5-day windows were not considered in lunar cycle analyses. Monthly analyses grouped data by calendar month.

Individuals were considered to have survived if the tag remained attached and recorded continual vertical and/or horizontal movements for a period of at least 10 days after release. The 10-day duration was selected as a period short enough to minimize observations of natural mortality but long enough to detect mortality directly resulting from the capture/tagging event. Tags that had data consistent with survival but released prematurely before 10 days were not included in the analysis of post-release mortality. A mortality could be inferred from mrPAT inclinometer readings if an individual died and sank to the ocean floor resulting in a nearly vertical $\left(0^{\circ}\right)$ mean inclinometer reading. Mortality could be inferred from X-Tags and PTT-100s if a specimen died and sank to the ocean floor resulting in data showing a nearly constant relatively low temperature combined with an extended constant pressure followed by eventual tag release. Predation deaths would not be detected if a tag separated from its specimen. Post-release mortality rate confidence intervals were obtained using estimation methods developed by Goodyear [7] with 10,000 trial simulations, a natural mortality rate of 0.2 , and a survival expression period of 10 days.

\section{Results}

A total of 36 PSATs (7 MTI X-Tags, 3 MTI PTT-100s, and $26 \mathrm{WC}$ mrPATs) were attached to 36 cobia caught in Virginia waters in August 2016 and August-September 2017. The size of fish tagged ranged from 96.5 to $150 \mathrm{~cm}$ TL with estimated weights of 6.8 to $27.3 \mathrm{~kg}$ (Table 1). The most prevalent size class were fish 96.5 to $101.6 \mathrm{~cm}$ TL (Fig. 1). This was the most frequently encountered size class above our pre-established minimum length for tagging, and several tags were deployed by a cooperating charter captain whose clients wished to retain legalsized fish (>101.6 cm TL), but were willing to tag and release fish below the Virginia minimum size or larger fish once they reached their bag limit. Fight times ranged from 0.75 to $15 \mathrm{~min}$ after hooking, and fish experienced air exposure times (landing, hook removal, and tagging) of approximately 1.5 to $4.5 \mathrm{~min}$ (Table 1 ). Eight of the tagged cobia were hooked deeply with the hook lodged inside the esophagus or gut. For these fish, the fishing line was cut as close to the hook as possible, and the fish was released with the hook in place.

\section{Tag reporting and performance}

Twenty-four PSATs transmitted data, 11 did not report, and 1 tag reported but provided no useable data (Table 2). Of the 24 tags that reported useable data, 19 released prematurely (1 X-Tag, 1 PTT-100, and 17 mrPATs), remaining attached to the fish for periods ranging from 1 to 99 days (Table 2). Five tags (3 X-Tags, 1 PTT-100, and $1 \mathrm{mrPAT}$ ) remained attached to fish for the entire 6-month programmed deployment duration and successfully reported data. The 11 non-reporting tags consisted of 3 X-Tags and 8 mrPATs. One PTT-100 reported after 6 months but very few transmissions were received, and those provided no useable data or location information. In aggregate, the 24 reporting tags provided a total of 1686 data-days.

\section{Post-release survival}

Of the 24 tags that reported useable data, all had temperature/depth (X-Tags and PTT-100s) or inclinometer (mrPATs) values that were consistent with survival. Included in the 24 reporting tags were 7 of the 8 cobia that were hooked deeply and released with the hooks still embedded in the fish. Twenty PSATs (including 4 of the 7 deep-hooked fish with reporting tags) met the minimum 10-day attachment threshold for assessing post-release survival. For each fish, the temperature/depth data demonstrated active vertical movements until the time of tag release (X-Tag \& PTT-100). All mean inclinometer readings were greater than $50^{\circ}$ from vertical for the day prior to tag release (mrPAT) suggesting that the fish was moving at that time (a non-moving fish would be evidenced with inclination near $0^{\circ}$ from vertical). Based on our observation of no post-release mortalities for the 20 cobia that carried tags for at least 10 days, we estimate a post-release mortality rate of $0 \%$. Using the Goodyear [7] method for a sample size of 20 tags, the $95 \%$ confidence interval around this estimate is $0 \%$ to $5 \%$. No inferences regarding survival or mortality can be drawn from the 11 tags that did not report or the one tag which reported but provided no useable data.

\section{Movement}

Twenty-four PSATs reported quality location data (ARGOS location codes 1, 2, \& 3) after surfacing, and 22 were deemed to accurately reflect the locations of the fish at the time of the first successful transmission (Fig. 2). Locations reported by premature mrPATs were considered accurate because these tags require only $6 \mathrm{~min}$ of "dry" time at the surface before transmitting data, 
Table 1 Deployment data for all 36 PSATs deployed on cobia for this study

\begin{tabular}{|c|c|c|c|c|c|c|c|}
\hline \# & Tag model & Deployment date & Fish TL (in.) & Est. weight (lb) & Fight time (min) & $\begin{array}{l}\text { Air exposure } \\
\text { (min) }\end{array}$ & Hooking location \\
\hline 1 & X-Tag & $8 / 12 / 2016$ & 43 & 25 & $3: 31$ & $3: 50$ & Superficial \\
\hline 2 & X-Tag & 8/14/2016 & 46 & 30 & $5: 53$ & $2: 35$ & Superficial \\
\hline 3 & X-Tag & $8 / 17 / 2016$ & 51 & 45 & $2: 48$ & $1: 23$ & Superficial \\
\hline 4 & X-Tag & 8/17/2016 & 50 & 40 & $4: 20$ & $1: 40$ & Superficial \\
\hline 5 & X-Tag & $8 / 17 / 2016$ & 55 & 55 & NA & NA & Superficial \\
\hline 6 & X-Tag & $8 / 20 / 2016$ & 38 & 18 & $1: 40$ & $2: 50$ & Superficial \\
\hline 7 & X-Tag & $8 / 30 / 2016$ & 49 & 40 & $4: 32$ & $1: 43$ & Superficial \\
\hline 8 & PTT-100 & $8 / 25 / 2017$ & 48 & 40 & $1: 45$ & $2: 35$ & Deep \\
\hline 9 & PTT-100 & $9 / 04 / 2017$ & 50 & 40 & $0: 45$ & $2: 00$ & Superficial \\
\hline 10 & PTT-100 & 9/04/2017 & 51 & 45 & $15: 00$ & $2: 00$ & Deep \\
\hline 11 & mrPAT & 8/03/2017 & 42 & 22 & $3: 27$ & $3: 13$ & Superficial \\
\hline 12 & mrPAT & 8/03/2017 & 38 & 19 & $3: 03$ & $2: 49$ & Superficial \\
\hline 13 & mrPAT & 8/03/2017 & 38 & 18 & $1: 49$ & $2: 05$ & Superficial \\
\hline 14 & mrPAT & $8 / 05 / 2017$ & 49 & NA & $10: 00$ & $2: 00$ & Superficial \\
\hline 15 & mrPAT & 8/06/2017 & 38 & 15 & $7: 00$ & $2: 00$ & Superficial \\
\hline 16 & mrPAT & 8/09/2017 & 59 & 60 & 10:00 & $3: 00$ & Superficial \\
\hline 17 & mrPAT & 8/09/2017 & 43 & 24 & $6: 48$ & $2: 41$ & Superficial \\
\hline 18 & mrPAT & 8/10/2017 & 42.5 & 26 & $3: 09$ & $3: 08$ & Superficial \\
\hline 19 & mrPAT & 8/10/2017 & 45 & 28 & $2: 32$ & $3: 44$ & Deep \\
\hline 20 & mrPAT & 8/13/2017 & 38 & 18 & $2: 10$ & $2: 02$ & Superficial \\
\hline 21 & mrPAT & $8 / 17 / 2017$ & 40 & 21 & NA & $2: 00$ & Superficial \\
\hline 22 & mrPAT & 8/17/2017 & 42 & 22 & $3: 13$ & $2: 41$ & Deep \\
\hline 23 & mrPAT & 8/19/2017 & 40 & 21 & $3: 40$ & $2: 04$ & Superficial \\
\hline 24 & mrPAT & 8/20/2017 & 38 & 20 & $2: 00$ & $2: 30$ & Superficial \\
\hline 25 & mrPAT & $8 / 25 / 2017$ & 42 & 24 & NA & $3: 12$ & Superficial \\
\hline 26 & mrPAT & $8 / 26 / 2017$ & 40 & 20 & $5: 10$ & 3:02 & Superficial \\
\hline 27 & mrPAT & $8 / 26 / 2017$ & 39.5 & 20 & $3: 30$ & $2: 20$ & Superficial \\
\hline 28 & mrPAT & 8/27/2017 & 44 & 23 & $8: 00$ & $4: 00$ & Superficial \\
\hline 29 & mrPAT & $8 / 27 / 2017$ & 43 & 22 & $4: 00$ & $2: 00$ & Deep \\
\hline 30 & mrPAT & 8/27/2017 & 42 & 21 & $2: 00$ & $3: 00$ & Deep \\
\hline 31 & mrPAT & $9 / 03 / 2017$ & 38.5 & NA & $3: 26$ & $2: 12$ & Deep \\
\hline 32 & mrPAT & $9 / 04 / 2017$ & 42 & NA & $5: 00$ & $2: 00$ & Superficial \\
\hline 33 & mrPAT & 9/08/2017 & 39 & 19 & $2: 38$ & $2: 59$ & Superficial \\
\hline 34 & mrPAT & 9/09/2017 & 39 & 15 & $3: 10$ & $2: 07$ & Superficial \\
\hline 35 & mrPAT & 9/09/2017 & 38 & 18 & $2: 10$ & $4: 22$ & Superficial \\
\hline 36 & mrPAT & $9 / 17 / 2017$ & 39 & 18 & $4: 37$ & $2: 05$ & Deep \\
\hline
\end{tabular}

$T L$ total length, $N A$ indicates information not available

with positions noted by the next passing ARGOS satellite. Locations obtained from two PSATs were excluded because too much time had elapsed between tag separation and first location report (13 and 98 days). One X-Tag (\#7) released after an 81-day attachment period and floated at the surface for 4 days before the constant depth release was activated and data transmission commenced. Based on prevailing currents (primarily the Gulf Stream) and the 4-day drift trajectories of three tags that popped up near the continental shelf break off North Carolina and South Carolina, we inferred that the tag (\#7) originally surfaced near the continental shelf break in the area off Wilmington, NC.

The five PSATs that remained attached for the full 6-month period help to define overwintering locations of cobia caught in Virginia waters, and the locations and dates of first transmissions of those PSATs that released prematurely provide insights into the timing of migratory behavior of fish leaving Virginia waters for overwintering areas. The six PSATs that reported in August, all within a 


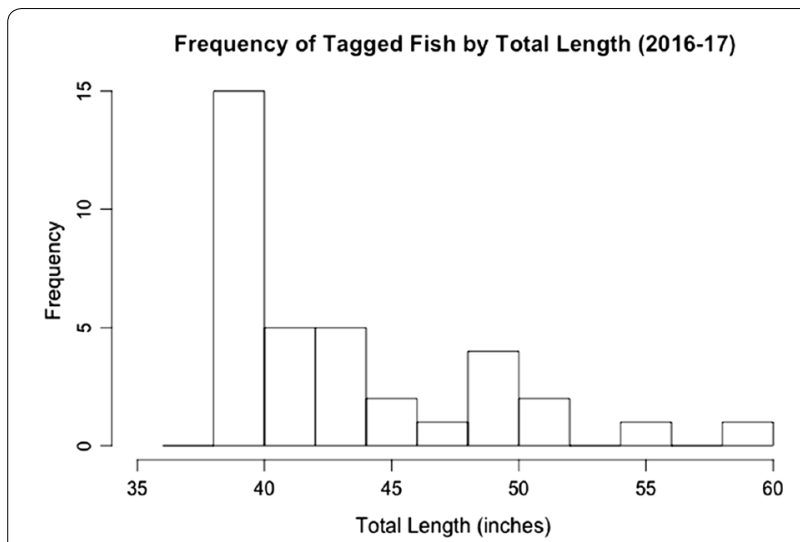

Fig. 1 Distribution of the total lengths of cobia tagged with pop-up satellite archival tags in this study. The majority of cobia fell in the 38-40 in size class, although specimens up to 59 in total length were included

few weeks of deployment, surfaced in Chesapeake Bay or coastal Virginia waters (Fig. 2). Of the three PSATs that detached and reported in September, two were in Virginia waters, and the third first transmitted from waters offshore of North Carolina. Four PSATs detached and reported in October: one indicated movement north into the Maryland portion of the Chesapeake Bay, one surfaced in Virginia waters, and two indicated that cobia had moved into waters south of Hatteras, NC. The four PSATs that detached and reported in November were more geographically scattered: one surfaced offshore of Savannah, GA, and three had first transmissions in waters near the shelf break off North Carolina. No tags reported in December or January. The five PSATs that remained attached for the full 6-month duration reported cobia in waters offshore of Florida, South Carolina, and North Carolina during February and early March. With the exception of the one tag reporting from the Maryland portion of Chesapeake Bay (not far from where the fish was originally tagged), all tags attached to cobia for at least 30 days demonstrated net southern movements for the period of September to early March. The reporting tags also showed that cobia tend to move into offshore

Table 2 Tag reporting information, including tag type, deployment date, fish total length TL (inches), deployment duration (days), net displacement $(\mathbf{k m})$, and percentage of transmissible data received

\begin{tabular}{|c|c|c|c|c|c|c|}
\hline$\#$ & Tag model & Deployment date & Fish TL (in) & $\begin{array}{l}\text { Deployment duration } \\
\text { (days) }\end{array}$ & $\begin{array}{l}\text { Net displacement } \\
(\mathrm{km})\end{array}$ & Data \% \\
\hline 2 & X-Tag & $8 / 14 / 2016$ & 46 & 192 & 982 & 21 \\
\hline 3 & X-Tag & $8 / 17 / 2016$ & 51 & 188 & 203 & 45 \\
\hline 6 & X-Tag & 8/20/2016 & 38 & 189 & 312 & 38 \\
\hline 7 & X-Tag & $8 / 30 / 2016$ & 49 & 81 & $250^{a}$ & 70 \\
\hline 8 & РTT-100 & $8 / 25 / 2017$ & 48 & 86 & - & 72 \\
\hline 9 & PTT-100 & 9/04/2017 & 50 & 194 & 444 & 44 \\
\hline 12 & mrPAT & 8/03/2017 & 38 & 40 & 59 & 100 \\
\hline 16 & mrPAT & 8/09/2017 & 59 & 13 & 24 & 100 \\
\hline 17 & mrPAT & 8/09/2017 & 43 & 55 & 34 & 100 \\
\hline 19 & mrPAT & $8 / 10 / 2017$ & 45 & 9 & 20 & 100 \\
\hline 21 & mrPAT & 8/17/2017 & 40 & 99 & 721 & 100 \\
\hline 22 & mrPAT & 8/17/2017 & 42 & 96 & 418 & 100 \\
\hline 23 & mrPAT & 8/19/2017 & 40 & 11 & 48 & 100 \\
\hline 24 & mrPAT & 8/20/2017 & 38 & 6 & 23 & 100 \\
\hline 25 & mrPAT & $8 / 25 / 2017$ & 42 & 180 & 459 & 56 \\
\hline 26 & mrPAT & $8 / 26 / 2017$ & 40 & 30 & 21 & 100 \\
\hline 28 & mrPAT & 8/27/2017 & 44 & 5 & 25 & 100 \\
\hline 29 & mrPAT & 8/27/2017 & 43 & 1 & 3 & 100 \\
\hline 30 & mrPAT & 8/27/2017 & 42 & 4 & 43 & 100 \\
\hline 31 & mrPAT & 9/03/2017 & 38.5 & 66 & 232 & 100 \\
\hline 32 & mrPAT & 9/04/2017 & 42 & 32 & 175 & 100 \\
\hline 34 & mrPAT & 9/09/2017 & 39 & 57 & - & 18 \\
\hline 35 & mrPAT & 9/09/2017 & 38 & 33 & - & 100 \\
\hline 36 & mrPAT & 9/17/2017 & 39 & 22 & 260 & 100 \\
\hline
\end{tabular}

a Indicates an estimated displacement using an approximate pop-up location based on currents and trajectory of a tag that surfaced in the same area. A dash represents no usable data 


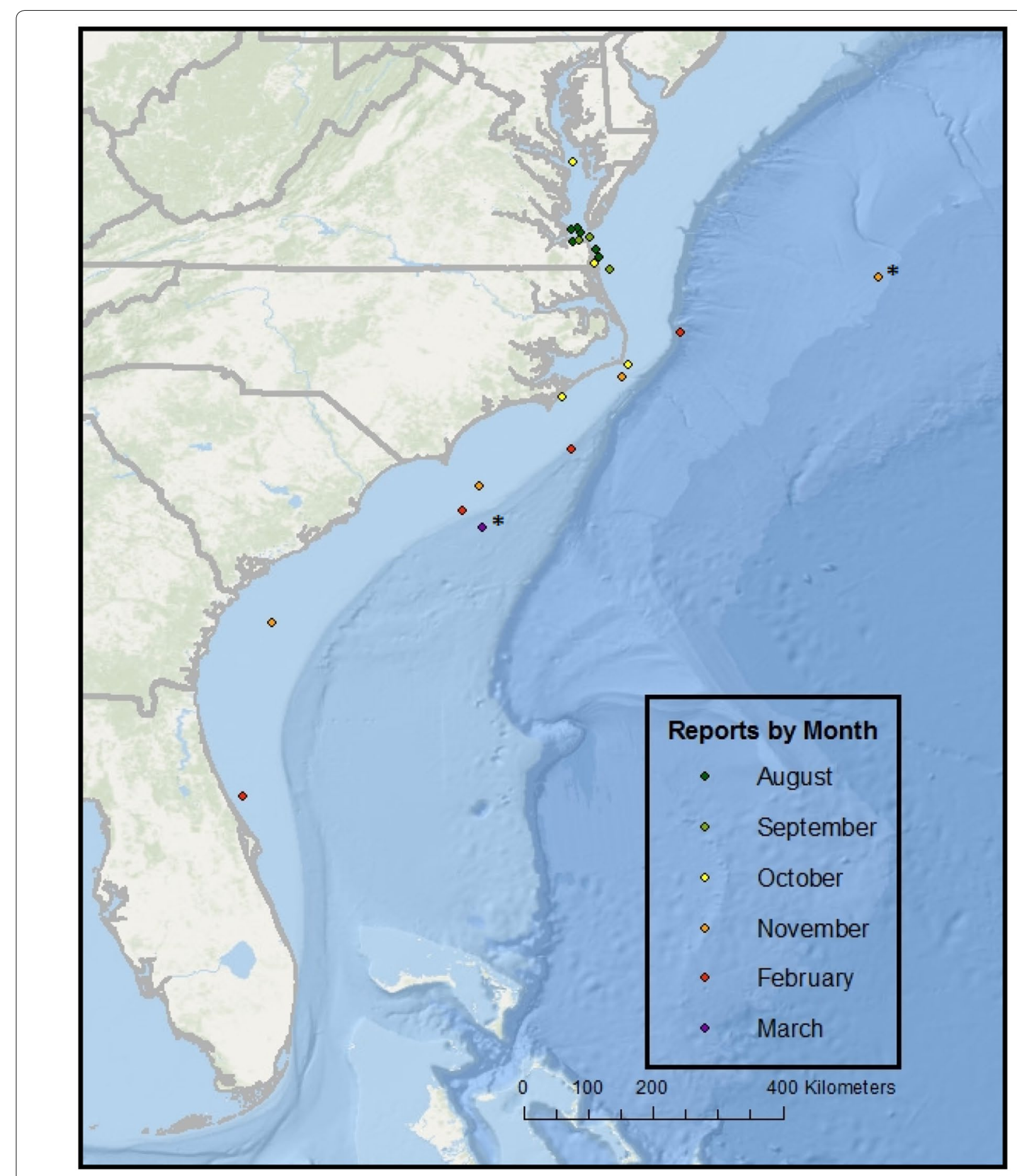

Fig. 2 A map showing the first location reported by each tag. Each point represents one cobia tagged in Virginia waters, color-coded by its month of tag report. The orange (November) location marked with an asterisk $\left(^{*}\right)$ is the location marked by the X-Tag that floated on the surface for 4-days prior to giving this first location; it was likely near the continental shelf edge offshore of Wilmington, NC when it separated from its specimen.

The purple (March) location marked with an asterisk $\left(^{*}\right)$ is the first location given by the PTT-100 that floated for 13 days before being located; it is difficult to approximate the drift trajectory, although it is reasonable to infer that the fish was southwest of this point prior to tag release 
waters starting in November. All tags reporting locations prior to 15 November (offshore of Maryland, Virginia, and North Carolina) were within $15 \mathrm{~km}$ of shore (mean $7.7 \mathrm{~km}$ ), while all first transmission locations after 15 November (offshore of North Carolina, South Carolina, Georgia, and Florida) were at least $15 \mathrm{~km}$ from the nearest shoreline (mean $61.7 \mathrm{~km}$ ), with the furthest tag being $77 \mathrm{~km}$ from the nearest shoreline.

The mean daily displacement of all specimens was $4.0 \mathrm{~km} \pm 0.7 \mathrm{~km} \mathrm{SE}$ (Table 2). The tag with the northernmost reporting location had the smallest mean daily displacement, $0.6 \mathrm{~km}$, over the course of its 55-day tag attachment (Table 2, tag \#17). Cobia can undertake displacements of more than $10 \mathrm{~km}$ per day, demonstrated by two specimens, one that traveled a net distance of $43 \mathrm{~km}$ over 4 days (tag \#30) and another fish with a $260 \mathrm{~km}$ displacement over 22 days (tag \#36).

\section{Habitat utilization}

Temperature and pressure (depth) data recorded in 15or 30-min intervals and transmitted by the four X-Tags and two PTT-100 PSATs were used for analyses of habitat utilization. Data recoveries for these tags ranged from 21 to $72 \%$ of the transmissible data. Daily minimum and maximum temperature data were also received from 18 WC mrPATs, but were not used in the following habitat utilization analyses unless otherwise noted.

The maximum and minimum recorded temperatures of water occupied by cobia were $30{ }^{\circ} \mathrm{C}$ and $12{ }^{\circ} \mathrm{C}$, respectively. Raw and weighted distributions of all temperature observations were assessed. These temperature distributions are limited, as they only include data collected from August through March, and are skewed by a greater number of tags reporting data for the months of September and October. The raw and weighted temperature distributions appear quite similar, but a Chi square test comparing the distributions indicated that they are significantly different $(p<0.05)$.

The monthly mean water temperature occupied by cobia decreased from $27^{\circ} \mathrm{C}$ in August to $19^{\circ} \mathrm{C}$ in February (Fig. 3). Distributional Chi square tests of the temperatures cobia occupied showed significant differences from month to month. Applying the same technique to temperatures reported for day and night yielded significant test statistics $(p<0.05)$ for all months but these significant results are due to the large number of observations rather than a true substantive difference. Qualitatively, there are no major differences noted between the temperatures cobia occupied during the day and night for any of the 8 months of the study. Similarly, no meaningful differences were noted in temperature distributions by lunar phase in any month in spite of significant Chi square distribution tests $(p<0.05)$, an

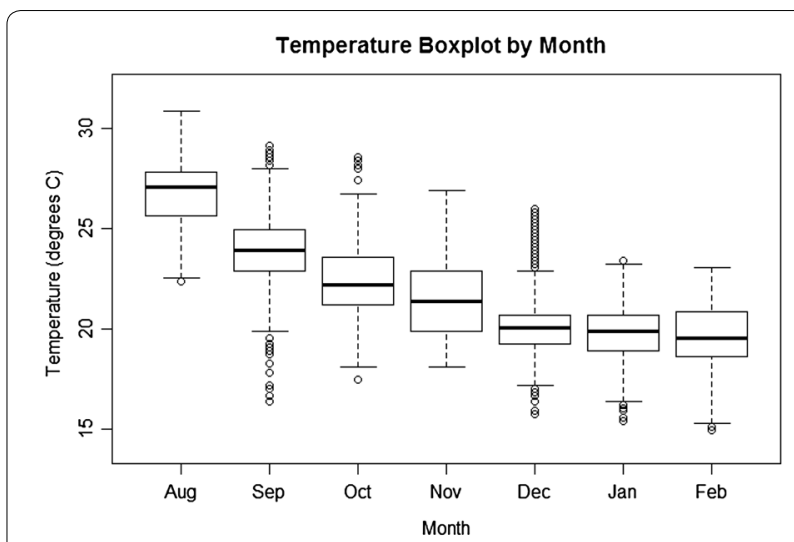

Fig. 3 Boxplot of cobia temperature observations depicting mean temperatures and the median $50 \%$ of observations by month. The dark bar in each box is the mean of that month's temperature observations. The boxes encompass the 25th to 75th percentile of observations. The "whisker" lengths are determined by the lesser of the most extreme observation for the month or 1.5 times the inter-quartile range (IQR). The points outside the whiskers are all observations more extreme than 1.5 times IQR

artifact of the large number of observations. Very few observations $(2.2 \%)$ reported water temperatures less than $18{ }^{\circ} \mathrm{C}$.

Cobia occupied depths ranging from the surface to a maximum of $118 \mathrm{~m}$. Raw and weighted distributions of all depth observations from the X-Tags and PTT100 PSATs were assessed as similar, but a Chi square comparison indicated significant differences $(p<0.05)$. Boxplots of monthly depth observations (Fig. 4) show a gradual increase in depth occupied over time, from a mean depth of $3.8 \mathrm{~m}$ in August to a mean depth of $32.1 \mathrm{~m}$ in February. Although Chi square tests indicate significant differences $(p<0.05)$ when comparing the distribution of depths occupied, there are no substantive differences noted in the depths occupied by cobia during the day and night for any month, or by lunar phase for any month. Depth utilization of individual fish was assessed and no substantive differences were noted between fishes for any month, even though their movement patterns widely varied.

Cobia exhibited a strong seasonal association with the surface. During the month of August, 38\% of depth observations were in the top $1 \mathrm{~m}$ of the water column. This value dropped to $25 \%$ in September, $6 \%$ in October, and less than $2 \%$ for the months November through February. Chi square tests yield significant differences $(p<0.05)$ in the distribution of depths occupied by cobia for each month, although these differences are only substantively meaningful for August, September, and October; depth distributions in November through February are qualitatively similar. 


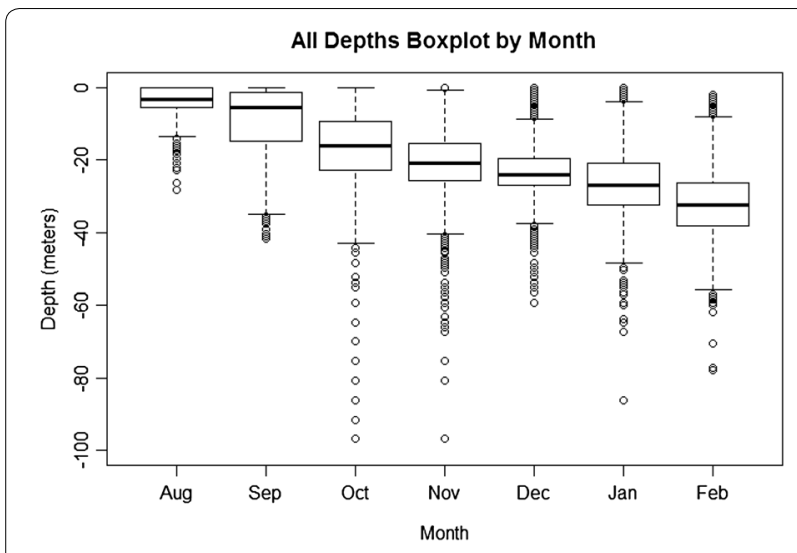

Fig. 4 Boxplot of cobia depth observations by month. The dark bar in each box is the mean of that month's depth observations. The boxes encompass the 25th to 75th percentile of observations. The "whisker" lengths are determined by the lesser of the most extreme observation for the month or 1.5 times the inter-quartile range (IQR). The points outside the whiskers are all observations more extreme than 1.5 times IQR. Mean depth decreases each month from a mean of $3.8 \mathrm{~m}$ in August to $32.1 \mathrm{~m}$ in February

\section{Discussion}

The goal of this study was to use pop-up satellite archival tag technology to increase our knowledge of the post-release survival, movements, and habitat utilization of cobia that summer in Virginia waters. To that end, we obtained a total of 1686 cobia data-days, covering a time period from August to March, and waters from Chesapeake Bay to off Daytona Beach, FL. While PSATs are extremely useful tools for studying large, migratory marine species such as cobia, there are challenges with the application of the technology. Those challenges impacted this study in a variety of ways including tag deployment, tag reporting, and premature release.

We planned to deploy a total of 41 tags, beginning in August of each year to reduce the probability of a fish being recaptured before it left Virginia waters. In all, we were able to deploy 36 of the tags, but a number of factors (weather, vessel availability, and fish catchability) prevented all PSATs from being deployed. Even though we commenced tagging late in the season, two of the tagged cobia were recaptured in Virginia waters within 2 weeks of release. One fish was re-released with its X-Tag intact, but that PSAT did not report (tag \#4). The second recaptured fish was harvested, and the angler returned the mrPAT tag (\#16).

\section{Tag reporting and performance}

Of the 36 PSATs deployed, 11 did not report, one reported but provided no useful information, and 19 of the 24 tags reporting useful information released prior to the scheduled 6-month time period. Relative to previous PSAT studies in our laboratory (e.g., $[8-10,12])$, we were surprised by the high number of non-reporting tags and high number of premature releases in this study. The results of the current study, however, are not out of character with other studies that have used PSAT technology on fishes. Musyl et al.s [18] meta-analysis of studies that deployed 731 PSATs on 19 species calculated a mean tag reporting rate of $79 \%$ ( $21 \%$ of the tags did not report), and a mean premature release rate of $82 \%$. These values are comparable to the current study which had a tag reporting rate of $69 \%$ and a premature release rate of $80 \%$.

While premature release occurred with all three tag models used in this study, the rate was surprisingly high for the mrPATs, only one of which remained attached for the full 6-month deployment. Premature releases result in lost data-days. Transmitted data indicated that all 16 prematurely reporting mrPATs initiated the release and transmission cycle prematurely because they were identified as floating at the surface by the tag's programming [the water sensor was "dry" for a total of at least $6 \mathrm{~min}$ (at 3-s sampling intervals) in any rolling 2-h window]. It is probable that some of these tags separated from the fish and floated to the surface at which time the conditional release feature was activated, similar to what likely occurred for one X-Tag and one PTT-100. Several mechanical issues could be responsible for early separation, including failures involving the anchor, tether, nose cone, or release wire. Premature release can also result from tag predation by another fish that pulls out the anchor or breaks the release wire. Information provided by the MTI tags on cobia habitat utilization suggests that the default conditional (constant depth) release setting on the mrPATs may have been inappropriate for cobia and increased the possibility of a conditional release. Depth data showed that cobia spend $38 \%$ and $25 \%$ of their time in the top $1 \mathrm{~m}$ of the water column during the months of August and September, respectively. Of the 16 premature mrPAT releases, 9 occurred during these months, with another 4 premature releases in October, and 3 in November. It is possible that when a cobia basks very near the water's surface, the water sensor at the top of the tag is repeatedly exposed to air for extended periods, resulting in a conditional release. The transmitted data do not allow one to determine if any of the 16 mrPATs were attached to the fish at the time the release sequence was initiated. Three of the tags that released prematurely subsequently washed up on North Carolina beaches and were found by beachcombers. All three tags lacked the tether, anchor, and nosecone, which would have been jettisoned as part of the release sequence whether or not the tag was attached to the fish, and none exhibited any physical damage suggestive of tag predation. 
The mrPAT tag is relatively new, and has only been featured in two published studies. One study reported $100 \%$ reporting rate with 18 tags attached to Greenland sharks (Somniosus microcephalus) with programmed deployment durations of up to 45 days [14]. The second study deployed 10 mrPATs on Japanese eels (Anguilla japonica) with programmed durations of up to 121 days [3]. In that study, 6 tags were "lost" (did not report) and 4 reported prematurely. Our observed non-reporting rate of $31 \%$ for mrPATs is much larger than the rate of $0 \%$ reported by Hussey et al. [14], but considerably lower than Chen et al's [3] $60 \%$ of tags lost.

Three of seven X-Tags remained attached for the full programmed 6-month deployment period, but delays in initial reporting were noted for all three of these tags, even though release was initiated at 6 months as programmed. The depth data suggest that the PSATs remained attached to the fish for 5 to 9 days after activation of the release sequence followed by a rapid rise to the surface and immediate successful transmissions which characterizes most releases. From these observations, we suspect that the release wires on the tags with delayed transmissions were not fully corroded during the release sequence, and extra time (and/or fish movement) was needed to break free. The delay in separation resulted in tags transmitting underwater to no avail, consuming battery power. Once the tags surfaced and were able to successfully transmit, the limited battery life resulted in reduced data recovery rates. Other researchers have encountered similar problems with tag release mechanisms, and tagged bluefin tuna (Thunnus thynnus) and striped bass (Morone saxatilis) have been recaptured with an undamaged, non-reporting X-Tag still attached more than a year after the scheduled release date ([16]; Graves and Horodysky, unpublished data).

All three of the PTT-100s reported after 6 months as programmed, but there were issues with data recovery for two of the tags. As previously noted, the constant depth release of the PTT-100s, which has a pressure sensitivity of $\pm 10 \mathrm{~m}$, was not activated as it would likely result in premature release from cobia in the relatively shallow waters of Chesapeake Bay. By not activating the constant depth release, however, we would only get a report from the tag at the end of its 6-month deployment, regardless of whether or not it remained attached to a fish for the entire period. Of the two PTT-100s with reporting issues, one tag reported at the programmed time, but its transmissions were so few and without reliable location that no useable data were recovered. This tag likely separated from the fish prematurely, was beached, and partially covered by debris, hampering effective transmissions at the end of 6 months. The other tag did not report until 13 days after its programmed release date.
The most probable explanation for the reporting delay is that the tag released from the fish on time, but encountered debris that interfered with the antenna as it rose to the surface. When the tag successfully transmitted, the remaining battery life was limited and only $44 \%$ of the transmissible data were received.

Although this study encountered many challenges with PSAT retention and data recovery, the devices remain one of the most effective methods for obtaining fishery-independent data on mortality, location, and habitat utilization. Though imperfect, PSATs were the best tool available for this study, and remain one of the best options for future studies [27].

\section{Post-release survival}

This is the first study of post-release survival of cobia caught in the recreational fishery. We tagged all fish made available to us, regardless of condition, provided that they met a minimum length established for each tag model. The minimum length criteria were set in an effort to ensure that fish survival would not be significantly impacted by the presence of a towed PSAT. Although the effects of PSATs on teleost fish physiology have not been evaluated, a study of juvenile sandbar sharks (Carcharhinus plumbeus) smaller than the cobia tagged in this study, noted a change of less than $5 \%$ in the metabolic rate and negligible impacts on swimming kinematics when MTI $\mathrm{X}$-tags were attached to the sharks [17]. Considering these results, we conclude that the PSATs used in this study had negligible impact on the swimming kinematics and metabolism of adult cobia.

In this study, we inferred no post-release mortalities from the 24 tags that reported data, and this number included 7 of the 8 cobia that were hooked deeply. Twenty tags remained attached to cobia for at least 10 days, including 4 from deeply hooked fish, a time threshold we established as sufficient to observe mortality directly resulting from the trauma and stress of capture, tagging, and release. This resulted in an observed post-release mortality rate of $0 \%$. The results demonstrate that cobia that are deeply hooked and released with the hook still embedded in the fish can survive. Two of these fish retained tags for periods of 86 and 96 days, suggesting that there were no major long-term effects from releasing the fish with the hook in place.

An important assumption for post-release mortality estimates is that specimen handling is representative of typical recreational practices. In this study, angling and landing of fish was done solely by research volunteers using methods of their choosing, not directed by the researchers. One aspect of potential bias, however, is that the research volunteers may have been more conservation-oriented than the average angler, and were more 
respectful of the animals during the capture and release process. Throughout the study, we observed that the anglers treated all cobia with care. For those that were deeply hooked, the line was cut and the hook was left in the fish's esophagus or gut. Not all anglers may be willing to "lose" a hook in a released cobia, and may cause additional physical trauma trying to remove a hook. If this is a common occurrence, our estimate of post-release survival rate may be biased low. This may be offset, however, by the fact that specimens in this study experienced the additional trauma of tag anchor insertion followed by the increased energetic demand of towing a PSAT, factors that could bias post-release mortality rates upward.

Non-reporting PSATs complicate estimates of postrelease survival. Tags may fail to report for a variety of reasons, many of which have nothing to do with the condition of the animal carrying the tag. Predation and scavenging of PSATs attached to highly migratory species by large sharks has been noted from data transmitted by tags that continued to function after ingestion and subsequent regurgitation. It is likely that some PSATs do not survive such an ordeal (being compromised at the time of ingestion), and do not successfully transmit data, resulting in a non-reporting tag. However, it is assumed that this would be a rare event, and most studies have opted to not include non-reporting tags in estimates of postrelease survival $[15,18]$. For consistency, in this study we excluded all non-reporting tags from our mortality estimates.

There are no previous estimates of cobia post-release mortality with which to compare our estimate of $0 \%$. Graves and Horodysky (unpublished data) observed no post-release mortalities for 17 large red drum (Sciaenops ocellatus) caught in the Chesapeake Bay and tagged with PSATs for periods of 1-6 months. In contrast, in a metaanalysis of post-release mortality studies that included 20 saltwater species, Bartholomew and Bohnsack [1] noted 6 species that had mean post-release mortalities of less than $10 \%$, although post-release mortality rates exceeding $50 \%$ were observed for some species.

This first study of cobia post-release mortality confirms the observation of anglers that cobia are hardy fish, and have high survival rates following release when handled quickly and respectfully. Our estimate of a post-release mortality rate of $0 \%$ with a $95 \%$ confidence interval ranging from 0 to $5 \%$ provides support for the last assessment which assumed a post-release mortality rate of $5 \%$ for cobia released from the recreational fishery [23].

\section{Movements}

A goal of this study was to delineate the wintering areas for cobia that summer in Virginia waters. Only 8 tags remained attached until at least 15 November, however, and only 5 remained attached for the full 6-month deployment period. One fish migrated as far south as Daytona Beach, FL. Five tags, including three of the five full-duration tags, reported from waters offshore of North Carolina near the continental shelf break, suggesting that these waters are likely an important overwintering habitat for cobia that summer in Virginia waters.

The date and location of prematurely released tags demonstrate that cobia that summer in Virginia waters leave the area starting in August, although some may remain in local waters as late as early October. Tag popup locations show movement offshore in addition to southerly migration. All 8 tags that reported locations after 15 November were located more than $15 \mathrm{~km}$ from shore (mean $61.7 \mathrm{~km}$ ), while all 14 tags that reported prior to 15 November first transmitted from positions less than $15 \mathrm{~km}$ from the nearest coastline (mean $7.7 \mathrm{~km}$ ). The movement of cobia into offshore waters during the winter months is consistent with the results of recent acoustic studies that note a conspicuous absence of cobia reports from inshore receivers during the months of December through March [30]. Young et al. [30] tagged 146 cobia with acoustic transmitters and received reports in spring, summer, and fall months on multiple receivers, the majority of which were within $15 \mathrm{~km}$ of shore. The absence of reports of cobia from these acoustic receivers in December through March suggests that cobia are either not moving during this time, or they are not present in inshore areas with acoustic receivers. Together, these observations demonstrate a distinct offshore component to cobia movements in the late fall and winter.

The one fish in this study that traveled as far south as Daytona Beach, FL illustrates that some cobia found in Virginia waters during the summer do make extensive seasonal migrations. This individual is of particular interest because it moved well past the current stock boundary at the Georgia-Florida state line. If one only considers the PSATs that remained attached for the full 6-month duration in this study (a very limited sample size), one of five fish traveled across the current management boundary. Conventional tag return data since the 1980s also demonstrate some movement (3\%) of cobia from Virginia into Florida waters [21]. Recently, 1 of 13 cobia caught in Virginia waters during the summer and implanted with acoustic transmitters was reported from Florida waters during the winter. This fish was offshore of the coastal fixed array receivers and was detected by a Bureau of Ocean Energy Management autonomous wave glider [28]. Taken together, these observations demonstrate movement of cobia that summer in Virginia waters across the current management boundary. Further study 
is needed to obtain a precise estimate of movements across the current management boundary.

The light data provided by MTI tags have been used in other studies to describe in greater detail the likely travel paths of pelagic fishes undertaking large-scale movements [16, 25]. We considered using light- and temperature-based geolocation to study cobia movements in more detail but opted not to, believing such travel estimates would not prove particularly useful in this study. Traditional methods have relatively large errors $(\geq 100 \mathrm{~km})$ and our specimens traveled comparatively short distances (only 2 fish had net displacements exceeding $500 \mathrm{~km}$ ).

\section{Habitat utilization}

Prior to this study, little was known about cobia habitat utilization. The detailed depth and temperature records we obtained for 6 individuals for periods of up to 6 months provide considerable information on seasonal changes in cobia habitat utilization. Cobia that summer in Virginia waters move into deeper and cooler waters as the fall/winter season progresses, consistent with the PSAT location data showing that cobia move from coastal to offshore shelf waters to overwinter. During August, cobia occupied a mean depth of $3.8 \mathrm{~m}$ and begin occupying progressively deeper waters during the fall. By February, the mean depth occupied by cobia was $32.1 \mathrm{~m}$. This trend was consistent across individuals, including the one fish that traveled to Florida.

The PSAT depth data also show that cobia spend as much as $40 \%$ of their time in the top $1 \mathrm{~m}$ of the water column in warm months. This surface association makes it clear why sight-fishing for cobia can be so productive during the summer months and has gained popularity over the past decade $[2,29]$. Time spent in surface waters drops off quickly during the fall months.

The PSAT temperature data confirm that cobia are a warm water fish that spend the vast majority of time in waters $20^{\circ} \mathrm{C}$ or warmer. Even during January and February, less than $12 \%$ of the temperature records indicated cobia in waters $18{ }^{\circ} \mathrm{C}$ or colder. This is consistent with the observations of seasoned recreational anglers who will not actively target cobia until water temperatures reach $20{ }^{\circ} \mathrm{C}[2]$.

\section{Conclusions}

Fishery managers have had the unenviable task of managing cobia with limited biological information. Prior to this study, there were no data to support an estimate of post-release mortality and an extremely limited description of cobia habitat utilization. Likewise, movement data were restricted to those provided by conventional tag returns. The results of this study provide several new and useful insights into cobia behavior. Cobia are indeed a hardy species that can survive catch-and-release even with hooks lodged deep in their throats and the additional trauma of satellite tag anchor insertion. The observation of $0 \%$ post-release mortality is undoubtedly below the actual value, but the $95 \%$ confidence interval range of $0-5 \%$ post-release mortality suggests the $5 \%$ rate assumed by fishery managers is reasonable and likely precautionary. Knowledge of cobia movements and migrations are limited, but we are beginning to get a sense for where and when these fish travel. PSAT location reports combined with archived temperature and depth data show that cobia found in Virginia waters in the summer have largely left by October and occupy waters at least $15 \mathrm{~km}$ offshore of North Carolina, South Carolina, and Florida during the winter months. The limited number of tags that remained attached for the full deployment and successfully reported data prevent us from delineating overwintering areas, but the evidence suggests that North Carolina waters near the continental shelf break may be an important overwintering area for cobia that occupy Virginia waters during the summer. Some Virginia cobia overwinter at more southern locations, but more information is needed to know the fraction of cobia that undertake these movements. It is clear, though, that offshore movements in winter are at least as important as southerly migrations. Movement offshore is almost certainly temperature-driven, as cobia have a clear affinity for waters $20^{\circ} \mathrm{C}$ or warmer. They also display marked seasonal differences in water column depth utilization which clearly affects their vulnerability to various fisheries.

\section{Acknowledgements}

We are indebted to the numerous boat captains and anglers who volunteered their vessels, time, and expertise to catch cobia for this project. We wish to thank Andrij Horodysky, Richard Brill, and Chris Hein for their advice during the study and their review of the manuscript. Funding for PSATs came from the Virginia Saltwater Recreational Fishing Development Fund, award RF 09-06. This paper is Contribution No. 3921 of the Virginia Institute of Marine Science, William \& Mary.

\section{Authors' contributions}

DRJ managed the study, conducted fieldwork, processed data, and wrote the manuscript. JEG aided in project planning, participated in fieldwork, and contributed substantially to the manuscript. Both authors read and approved the final manuscript.

\section{Funding}

Funding for PSATs came from the Virginia Saltwater Recreational Fishing Development Fund, award RF 09-06.

\section{Availability of data and materials}

All data used are available from the corresponding author on reasonable request.

\section{Ethics approval and consent to participate}

The experimental protocols used in this study were approved by the College of William \& Mary's Institutional Animal Care and Use Committee (IACUC-2016-07-25-11296-jegrav). 


\section{Consent for publication \\ Not applicable.}

\section{Competing interests}

The authors declare that they have no competing interests.

Received: 19 Auqust 2019 Accepted: 8 July 2020

Published online: 14 July 2020

\section{References}

1. Bartholomew A, Bohnsack JA. A review of catch-and-release angling mortality with implications for no-take reserves. Rev Fish Biol Fish. 2005; 15(1-2):129-54

2. Burnley R. Mid-atlantic cobia fishing run. In: Sport fishing. 2011. https:// www.sportfishingmag.com/species/fish-species/mid-atlantic-cobia-run/. Accessed 15 May 2018.

3. Chen SC, Chang CR, Han YS. Seaward migration routes of indigenous eels, Anguilla japonica, A. marmorata, and A. bicolor pacifica, via satellite tags. Zool Stud. 2018;57:21

4. Cochran B. Cobia season controversy has anglers angry. In: Bristol Herald Courier. Bristol. 2016. http://www.heraldcourier.com/outdoor/cobia -season-controversy-has-anglers-angry/article 40d36df0-0767-11e6af45-9fac35cfa550.html. Accessed 15 May 2018.

5. Daniel L. For the interstate fishery management plan for cobia. Atlantic States Marine Fisheries Commission Public Information Document. 2016. p. 1-19.

6. Federal Register. Docket No. 101206604-1758-02. Federal Register Rules and Regulations. 2017; 82(15): 8363-4.

7. Goodyear CP. Factors affecting robust estimates of the catch-andrelease mortality using pop-off tag technology. Am Fish Soc Symp. 2002;30:172-9.

8. Graves JE, Horodysky AZ. Asymmetric conservation benefits of circle hooks in multispecies billfish recreational fisheries: a synthesis of hook performance and analysis of blue marlin (Makaira nigricans) postrelease survival. Fish Bull. 2010;108(4):433-41.

9. Graves JE, Horodysky AZ, Latour RJ. Use of pop-up satellite archival tag technology to study postrelease survival of and habitat use by estuarine and coastal fishes: an application to striped bass (Morone saxatilis). Fish Bull. 2009;107(3):373-83.

10. Graves JE, Luckhurst BE, Prince ED. An evaluation of pop-up satellite tags for estimating postrelease survival of blue marlin (Makaira nigricans) from a recreational fishery. Fish Bull. 2002;100(1):134-42.

11. Hanisko DS, Drass DM, Pollack AG, Zapfe G. Distribution and abundance of cobia (Rachycentron canadum) larvae captured in ichthyoplankton samples during National Marine Fisheries Service and Southeast Area Monitoring and Assessment Program fishery-independent resource surveys. SEDAR58-SID-09. Southeast Data Assessment and Review, North Charleston, SC. 2018:1-14.

12. Horodysky AZ, Kerstetter DW, Graves JE. Habitat preferences and diving behavior of white marlin (Tetrapturus albidus) released from the recreational rod-and-reel and commercial pelagic longline fisheries in the western North Atlantic Ocean: implications for habitat-based stock assessment models. Col Vol Sci Pap ICCAT. 2004;56(1):160-8.

13. Huang CT, Miao TS, Nan FH, Jung SM. Study on regional production and economy of cobia Rachycentron canadum commercial cage culture. Aquacult Int. 2011;19:649-64.

14. Hussey NE, Orr J, Fisk AT, Hedges KJ, Ferguson SH, Barkley AN. Mark report satellite tags (mrPATs) to detail large-scale horizontal movements of deep water species: first results for the Greenland shark (Somniosus microcephalus). Deep Sea Res Part I Oceanogr Res Pap. 2018;134:32-40.

15. Kerstetter DW, Graves JE. Survival of white marlin (Tetrapturus albidus) released from commercial pelagic longline gear in the western North Atlantic. Fish Bull. 2006;104:434-44.

16. Lutcavage ME, Lam CH, Galuardi B. Seventeen years and $\$ 3$ million dollars later: performance of PSAT tags deployed on Atlantic bluefin and bigeye tuna. Col Vol Sci Pap ICCAT. 2015;71:1757-65.

17. Lynch SD, Marcek BJ, Marshall HM, Bushnell PG, Bernal D, Brill RW. The effects of pop-up satellite archival tags (PSATs) on the metabolic rate and swimming kinematics of juvenile sandbar shark Carcharhinus plumbeus. Fish Res. 2017:186:205-15.

18. Musyl MK, Domeier ML, Nasb-Lucas N, Brill RW, McNaughton LM, Swimmer JY, Lutcavage MS, Wilson SG, Galuardi B, Liddle JBZ. Performance of pop-up satellite archival tags. Mar Ecol Prog Ser. 2011;433:1-28.

19. NMFS. Recreational Fisheries Statistics Queries. 2017. http://www.st.nmfs. noaa.gov/recreational-fisheries/data-and-documentation/queries/index. Accessed 02 June 2017.

20. NOAA Southeast Regional Office. Annual Catch Limit Monitoring. 2017. http://sero.nmfs.noaa.gov/sustainable_fisheries/acl monitoring/index html, Accessed 02 June 2017

21. Perkinson M, Denson M, Franks J, Musick S, Poland S, Orbesen E. Evaluation of cobia movements using tag-recapture data from the Gulf of Mexicoand South Atlantic coast of the United States: SEDAR58-SID-05. Southeast Data Assessment and Review, North Charleston, SC. 2018;2018:1-16.

22. Perkinson M, Denson M. Evaluation of cobia movements and distribution using tagging data from the Gulf of Mexico and South Atlantic coast of the United States. Southeast Data, Assessment, and Review, SEDAR28DW05, North Charleston, South Carolina. 2012. p. 1-18.

23. SEDAR 28. SEDAR 28-South Atlantic Cobia Stock Assessment Report. Southeast Data Assessment and Review, North Charleston, South Carolina. 2013; p. 1-420.

24. Shaffer RV, Nakamura EL. Synopsis of biological data on the cobia Rachycentron canadum (Pisces: Rachycentridae). NOAA Technical Report NMFS 82. FAO Fisheries Synopsis 153. 1989. p. 1-21.

25. Sippel T, Eveson JP, Galuardi B, Lam C, Hoyle S, Maunder M, Kleiber P, Carvalho F, Tsontos V, Teo SL, Aires-da-Silva A. Using movement data from electronic tags in fisheries stock assessment: a review of models, technology and experimental design. Fish Res. 2015;163:152-60.

26. Smith JW. Life history of cobia, Rachycentron canadum (Osteichthyes: rachycentridae), in North Carolina waters. Brimleyana. 1995;23:1-23.

27. Thorstad EB, Rikardsen AH, Alp A, Økland F. The use of electronic tags in fish research - an overview of fish telemetry methods. Turk J Fish Aquat Sci. 2013;13(5):881-96.

28. Weng K, Crear D, Watkins B. VIMS Cobia Tagging Program. SEDAR58SID-11. Southeast data assessment and review, North Charleston, SC. 2018. p. 1-8.

29. Wittman R. Sight-fishing cobia off North Carolina. In: Sport fishing. 2018 https://www.sportfishingmag.com/sight-fishing-cobia-off-north-carol ina/. Accessed 15 May 2018.

30. Young J, Perkinson M, Brenkert K, Reyier E, Whittington J. Cobia Telemetry Working Paper. SEDAR58-SID-08. Southeast Data Assessment and Review, North Charleston, SC. 2018. p. 1-9.

\section{Publisher's Note}

Springer Nature remains neutral with regard to jurisdictional claims in published maps and institutional affiliations. 